\title{
The History of Pediatric Hospital Medicine in the United States, 1996-2019
}

\author{
Kenneth B Roberts, MD ${ }^{1 *}$, Erin Ragan-Stucky Fisher, MD, MHM²,3, Daniel A Rauch, MD ${ }^{4}$
}

'Department of Pediatrics, University of North Carolina School of Medicine, Chapel Hill, North Carolina; ${ }^{2}$ Department of Pediatrics, University of California San Diego School of Medicine/Rady Children's Hospital, San Diego, California; ${ }^{2}$ Rady Children's Hospital, San Diego, California; ${ }^{4}$ Department of Pediatrics, Tufts University School of Medicine, Boston, Massachusetts.

n 1996, internists Robert Wachter, MD, and Lee Goldman, MD, $\mathrm{MPH}$, coined the term "hospitalist" and predicted an "emerging role in the American health care system." ${ }^{1}$ Pediatrics was not far behind: In 1999, Dr Wachter joined Paul Bellet, MD, in authoring an article describing the movement within pediatrics. ${ }^{2} \mathrm{An}$ accompanying editorial, coauthored by a pediatric hospitalist and an office-based practitioner, attempted to answer which was "better" for a hospitalized child: A practitioner who knew the child and family or a hospitalist who might be more knowledgeable about the disease, its inpatient management, and how to get things done in the hospital? ? $^{3}$ The authors could not answer which model was better for an individual child with an invested primary pediatrician, but concluded that hospitalists have the potential to improve care for all children in the hospital- the future promise of Pediatric Hospital Medicine (PHM). This article traces the growth of PHM from 1996 to the present, highlighting developments that fueled the hospital movement in general and PHM in particular (Table).

\section{REGULATIONS FOSTER OPPORTUNITIES FOR HOSPITALISTS}

In the 7 years after the article by Drs Wachter and Goldman, a series of regulations fostered the adoption of hospitalists in teaching hospitals. The first was the reissuance in 1997 of Intermediary Letter 372, which specifies the requirements for attending physicians to bill Medicare. ${ }^{4}$ The common practice of jotting "agree with above" and cosigning resident notes was no longer sufficient: Attendings had to document that they personally provided services to patients beyond those of residents. As a demonstration of enforcement, records at the Hospital of the University of Pennsylvania in Philadelphia were audited, and a bill for $\$ 30$ million for overpayments and penalties was issued. ${ }^{4}$ Teaching hospitals took notice and instituted mechanisms to assure compliance with IL-372, not limited to patients insured by Medicare. The obvious effect on faculty was the requirement of considerably more time and involvement in direct patient care.

Later in the 1990s, the Accreditation Council for Graduate Medical Education (ACGME) introduced a new direction

*Corresponding Author: Kenneth B. Roberts, MD; Email: kenrobertsmd@ gmail.com.

Published online first March 18, 2020

Find additional supporting information in the online version of this article.

Received: September 4, 2019; Revised: December 24, 2019

Accepted: January 6, 2020

๑ 2020 Society of Hospital Medicine DOI 10.12788/jhm.3381 termed the Outcome Project, which led to two novel trainee competency domains: practice-based improvement and systems-based practice. ${ }^{5}$ The focus on quality improvement, patient safety, and systems was reinforced by two Institute of Medicine publications, To Err Is Human: Building a Safer Health System ${ }^{6}$ and Crossing the Quality Chasm: A New Health Care System for the 21st Century. ${ }^{7}$ Hospitalists had the opportunity to impact both patient care and the education of learners in two ways: Directly, by more actively participating in and closely supervising clinical care (per IL-372) and, indirectly, by improving hospital systems.

In 2003, the ACGME extended work hour restrictions implemented in New York State to the national level. ${ }^{8}$ The new requirements were intended to improve patient safety and increase trainee supervision, but also had the effect of reducing trainees' clinical experience. While responses of teaching institutions varied, training program changes generated an increased role for hospitalists. ${ }^{9}$

These changes occurred on a backdrop of changing models of healthcare payment that provided incentive to shorten length of stay (LOS) and shift care from inpatient to ambulatory settings, which increased the acuity and complexity of hospitalized patients. The pressure to increase efficiency and decrease LOS affected faculty, residents, and practitioners in the community. Managing care of inpatients from a distance became more difficult; rounding more than once a day was often required and was disruptive and inefficient, particularly for community practitioners who might have only one or two patients in the hospital. Moreover, the hospital electronic medical record (EMR) became an additional barrier for many practitioners to continue to provide hospital-based care. Systems often differed from those used in their offices, and even when this was not the case, using and maintaining efficiency in the different components of the EMR was difficult. The conversion from paper to electronic documentation and ordering may have contributed to some practitioners relinquishing care of their patients to hospitalists.

\section{PEDIATRIC HOSPITAL MEDICINE: THREE PARENT ORGANIZATIONS}

The development of PHM was aided by support from three separate organizations, each with a different role: the Society of Hospital Medicine (SHM), the American Academy of Pediatrics (AAP), and the Academic Pediatric Association (APA). SHM was founded the year after the article by Drs Wachter and Goldman as the "National Association of Inpatient Phy- 
sicians." The name was changed to Society of Hospital Medicine in 2003 to reflect the evolving field of hospital medicine. While the organization is largely comprised of internists, a pediatrician has been on its board since 1998, and a pediatrics committee (now Special Interest Group, SIG) has been in existence since 1999. (Appendix Tables 1a and 1b; Appendix Figures 1a and 1b). In 2005, an SHM task force was formed to define PHM-specific Core Competencies that could serve as a basis for curriculum building and a definition of the field. These inaugural PHM Core Competencies were endorsed by all three societies; published in 2010 in SHM's flagship journal, the Journal of Hospital Medicine ${ }^{10}$; and were recently revised to reflect changes to the field in the past decade. ${ }^{11}$ SHM has provided valuable opportunities for hospitalists to develop knowledge and skills, particularly in matters related to healthcare operations and leadership, and it serves as a way to keep PHM connected with the larger hospital medicine community.

The AAP initiated its efforts to engage hospitalists in 1998 with the creation of a Provisional Section on Hospital Medicine (SOHM) that became a full section a year later. (Appendix Table 2; Appendix Figure 2) The SOHM listserv ${ }^{\circledast}$, created in 2000, became a major vehicle for communication among hospitalists-including individuals who are not members of the SOHM — with more than 4,000 subscribers currently. Of the SOHM achievements noted in the Table, one deserves special mention: In 2006, SOHM formally recognized the large number of hospitalists in community hospitals and established a subsection with Karen Kingry Olson, MD, as inaugural leader. Many of the hospitalists in these sites provide care not only to children on inpatient units but also in areas such as the nursery, delivery room, and emergency department, functioning "like water on pavement-filling all the cracks in the hospital," as Eric Biondi, MD, MS, puts it. ${ }^{12}$ It is a credit to the AAP and the PHM community that individuals from community hospitals have specifically been afforded leadership roles. SOHM membership has grown considerably from around 100 at inception to 2,700 in 2019. Participation in the AAP keeps PHM connected to the larger pediatrics community.

The APA established a Hospital and Inpatient Medicine SIG in 2001, the name of which was changed to Hospital Medicine SIG in 2004 (Appendix Table 3; Appendix Figure 3; Note: There had been an Inpatient General Pediatricians SIG in 1992, before the term hospitalist was coined, but it only met once.) In 2003, APA was the first national pediatrics organization to sponsor a PHM meeting. The meeting attracted 130 registrants and was considered successful enough to warrant another meeting in 2005, this time with SHM and AAP joining as cosponsors. In 2007, the triple-sponsored meetings became annual events, with 1,600 registrants at the 2019 meeting. The success of the initial meeting also caught the attention of APA leadership in another regard: a concern that the name of the organization might interfere with retaining hospitalists in the fold. In 2007, the Ambulatory Pediatric Association became the Academic Pediatric Association..$^{13}$ Being connected with the APA affords PHM a connection to academic generalists and activities central to the APA, such as research and education.

\section{TABLE. Timeline of PHM Milestones}

1996 Robert Wachter and Lee Goldman coin term "hospitalist" and predict "emerging role."

1997 National Association of Inpatient Physicians founded (name changed to Society of Hospital Medicine, or SHM, in 2003).

Intermediary Letter 372 (IL-372) reissued by Medicare. ${ }^{4}$

1998 AAP creates Provisional Section on Hospital Medicine (becomes Section on Hospital Medicine, or SOHM, in 1999).

ACGME launches "The Outcome Project."

1999 Paul Bellet and Robert Wachter publish "Hospital Movement in Pediatrics," with accompanying editorial..$^{2,3}$

2000 Institute of Medicine publishes "To Err Is Human." 6

AAP SOHM creates listserv ${ }^{\circledast}$.

2001 Institute of Medicine publishes "Crossing the Quality Chasm."

APA creates Hospital and Inpatient SIG (renamed Hospital Medicine SIG in 2004).

2002 Research network, Pediatric Research in Inpatient Settings (PRIS), launched.

2003 ACGME issues national work hour restrictions for residents. ${ }^{8}$

APA convenes first PHM meeting sponsored by national pediatrics organization. First PHM textbook published ${ }^{28}$ (others followed ${ }^{29,30,31}$ ).

2005 AAP, APA, SHM convene first triple-sponsored national PHM meeting. AAP SOHM publishes "Guiding Principles for Pediatric Hospitalist Programs (revised in 2013). 22,23

First "modern" PHM fellowship opens at Children's National Medical Center in Washington, DC.

2006 AAP SOHM creates Subcommittee on Community Hospitals.

ABP Foundation publishes first of a series of articles about PHM. ${ }^{16}$

2007 Triple-sponsored national PHM meetings become annual events

Pediatric Hospital Information System (PHIS) publications increase.

2008 Value in Inpatient Pediatrics (VIP) network established (becomes part of AAP in 2011).

2009 Strategic planning "roundtable" convened..$^{14}$

2010 Pediatric Hospital Medicine Core Competencies published (revision due in 2020). ${ }^{10,1}$ AAP SOHM publishes "Physicians role in coordinating care of hospitalized children" (revised in 2018). ${ }^{24,25}$

2011 AAP launches Hospital Pediatrics journal. ${ }^{30}$

Joint Council on PHM formed (replaced by PHM Consortium in 2016)

First annual PHM fellows conference.

2012 PHM Strategic Planning Report published. ${ }^{17}$

2014 Advancing Pediatric Educator Excellence (APEx) program established by AAP (APA joins as cosponsor in 2015).

Proposal for subspecialty certification submitted to ABP (accepted 2015). ${ }^{19}$

2015 Council on Pediatric Subspecialties invites PHM to participate.

2016 American Board of Medical Specialties approves PHM as ABP subspecialty.

2017 ACGME agrees to accredit PHM fellowships.

2019 Curricular framework for fellowships published. ${ }^{24}$

PHM Entrustable Professional Activities published. ${ }^{25}$

First PHM subspecialty certification examination.

Abbreviations: AAP, American Academy of Pediatrics; ABP, American Board of Pediatrics; ACGME, Accreditation Council for Graduate Medical Education; APA, Academic Pediatric Association; SIG, Special Interest Group; PHM, Pediatric Hospital Medicine 


\section{CONSOLIDATION OF PEDIATRIC HOSPITAL MEDICINE}

In 2009, PHM leaders within SHM, APA, and AAP held a pivotal strategic planning "roundtable" to discuss the future of the field. ${ }^{14}$ A vision statement was developed, serving as a guide to the tasks needed to achieve the vision: "Pediatric hospitalists will transform the delivery of hospital care for children." Five areas were considered: clinical, quality, research, workforce, and structure. Clinical practice was defined as including both "direct patient care and leadership of the inpatient service." It was recognized that standardizing, disseminating, and increasing knowledge to improve clinical care was important, but so, too, was taking on leadership roles to improve systems and extend into areas such as sedation. Quality improvement was identified as the measure by which the value of PHM would be assessed. To further efforts in this area, a PHM Quality Improvement (QI) Collaborative work group was created. Research was clearly a necessary component to establish and advance the field. The Children's Hospital Association had launched the Pediatric Health Information System (PHIS) database in 1993, and PHIS began to flourish as a research database when Samir Shah, MD, MSCE, and Matt Hall, PhD, headed the Research Groups in 2007. Discussions to form an independent research network began in 2001, and, in 2002, the Pediatric Research in Inpatient Settings network (PRIS) was launched, led by Christopher Landrigan, MD, MPH. ${ }^{15}$ The APA provided organization support in 2006, but a redesign was considered necessary to further move the research initiative forward. ${ }^{15}$ A Research Leadership Task Force was created, resulting in a new PRIS Network Executive Council, chaired by Rajendu Srivastava, MD, MPH, until 2016, when Karen Wilson, MD, MPH, became chair. Clinical and workforce issues focused on the need to supplement residency training with added skills and knowledge to practice as a pediatric hospitalist. An Education Task Force was created, charged with developing "an educational plan supporting the PHM Core Competencies and addressing hospitalist training needs, including the role as formal educators." The task force was headed by Mary Ottolini, MD, MPH, MEd, who was aided by Jennifer Maniscalco, MD, MPH, MAcM. Regarding structure of PHM, the decision was made not to develop an independent society but to continue to function within and benefit from the resources of SHM, AAP, and APA, with a Joint Council on Pediatric Hospital Medicine (JCPHM). Established in 2011, the JCPHM included representatives of the AAP, APA, SHM, PRIS, VIP, community hospitals, and the Education Task Force. Erin Stucky Fisher, MD, MHM, served as the first chair. The JCPHM was replaced in the fall of 2016 by a Consortium on PHM, which consists of the chairs and chair elects of the AAP SOHM, the APA Hospital Medicine SIG, and the SHM pediatrics committee. The leadership rotates annually among the three organizations.

\section{PATH TO SUBSPECIALTY STATUS}

The American Board of Pediatrics (ABP) recognized the growing field of PHM and, through its foundation, commissioned a series of studies, the first of which was published in 2006 entitled "Hospitalists in children's hospitals: What we know now and what we need to know."16 It was not clear whether the PHM community would pursue subspecialty certification. The leaders of the 2009 "roundtable" meeting commissioned a Strategic Planning Committee (STP) led by Christopher Maloney, MD, PhD, and Suzanne Swanson Mendez, MD, to evaluate the best course of action: traditional ABP subspecialty certification, hospital medicine residency track (with or without additional fellowship), Recognition of Focused Practice (as implemented by the American Board of Internal Medicine and American Board of Family Medicine), mandatory mentorship program, or status quo with option for specialized training. There was considerable discussion of the alternatives in the PHM community. In 2012, the STP shared the results of Strengths-Weaknesses-Opportunities-Threats analyses-but did not issue a recommendation. ${ }^{17}$ The following year, a National PHM Leaders Conference was held to consider the various options. Participants concluded that the best path forward was to pursue subspecialty certification with a requirement for 2 years of fellowship (after a time-limited period for practice pathway eligibility). Two years of fellowship was a departure from the ABP's standard 3 years, but seemed acceptable based on the expectation that the research component would be integrated with clinical activities (eg, Ql), rather than separate bench research. The ABP Initiative on Subspecialty Clinical Training and Certification had recommended flexibility in the duration of fellowships, ${ }^{18}$ and PHM became the first discipline to take advantage of such flexibility. Following an 18-month review of multiple considerations, the $\mathrm{ABP}$ concluded that "children will be better served by establishing the discipline as a new subspecialty." 19

The decision to pursue subspecialty certification was not unanimously embraced by the PHM community, with particular concerns expressed regarding the impact on Med-Peds hospitalists and the future in community hospitals. These were considered by the individuals writing the formal proposal to the ABP, but have not been resolved. Moreover, criteria for eligibility for the certifying examination under the Practice Pathway ("grandparenting") evoked controversy, ${ }^{20}$ addressed by the ABP. ${ }^{21}$ The first subspecialty certifying examination was ultimately administered to $\sim 1,500$ pediatric hospitalists in 2019.

\section{THE ONGOING EVOLUTION OF PEDIATRIC HOSPITAL MEDICINE}

It is clear that PHM has established itself as a field, with networks for research and quality improvement, more than 50 fellowship programs, divisions in prestigious departments of pediatrics and children's hospitals, devoted journals and textbooks, and a well-attended annual meeting. PHM has set standards for the core competencies in $\mathrm{PHM}_{1}{ }^{11,12}$ for pediatric hospitalist programs, ${ }^{22,23}$ for coordinating the hospital care of children, ${ }^{24,25}$ for the curricular framework of fellowships, ${ }^{26}$ and for the Entrustable Professional Activities expected of a hospitalist. ${ }^{27}$ The vision for the future is that continued efforts in research, quality and systems improvement, and clinical care will, in fact, result in signifi- 
cant benefits for all hospitalized children. Such was the promise of PHM in the 1990s and remains so in 2019.

\section{Acknowledgments}

For prompting the project: Rachel Marek. For additions, corrections, and confirmations: David Alexander, Niccole Alexander, Paul Bellet, David Bertoch, Douglas Carlson, Laura Degnon, Kimberly Durham, Barrett Fromme, Sandy Gage, Matthew Garber, Karen Jerardi, Christopher Landrigan, Gail McGuinness, Jennifer Maniscalco, Sandy Melzer, Vineeta Mittal, Karen Kingry Olson, Mary Ottolini, Jack Percelay, Kris Rehm, Michael Ruhlen, Samir Shah, Suzanne Woods, and David Zipes.

Disclosures: The authors have nothing to disclose.

\section{References}

1. Wachter RM, Goldman L. The emerging role of "hospitalists" in the American health care system. N Engl J Med. 1996;335:514-517. https://doi. org/10.1056/NEJM199608153350713

2. Bellet PS, Wachter RM. The hospitalist movement and its implications for the care of hospitalized children. Pediatrics. 1999;103(2):473-477. https://doi org/10.1542/peds.103.2.473

3. Roberts KB, Rappo P. A hospitalist movement? Where to? Pediatrics. 1999;103(2):497. https://doi.org/10.1542/peds.103.2.497

4. Cohen JJ, Dickler RM. Auditing the Medicare-billing practices of teaching physicians-Welcome accountability, unfair approach. N Engl J Med. 1997;336(18):1317-1320. https://doi.org/10.1056/NEJM199705013361811

5. Swing SR. The ACGME outcome project: Retrospective and prospective. Med Teach. 2007;29(7):648-654. https://doi.org/10.1080/01421590701392903.

6. Institute of Medicine. To Err Is Human: Building a Safer Health System. Washington, DC: The National Academies Press; 2000.

7. Committee on Quality Health Care in America, Institute of Medicine. Crossing the Quality Chasm: A New Health System for the 21st Century. Washington, DC: National Academy Press; 2001

8. Accreditation Council for Graduate Medical Education. History of Duty Hours. Accessed January 16, 2020. https://www.acgme.org/What-We-Do/ Accreditation/Clinical-Experience-and-Education-formerly-Duty-Hours/History-of-Duty-Hours

9. Oshimura JM, Sperring J, Bauer BD, Carroll AE, Rauch DA. Changes in inpatient staffing following implementation of new residency work hours. J Hosp Med. 2014;9(10):640-645. https://doi.org/10.1002/jhm.2242

10. Stucky ER, Maniscalco J, Ottolini MC, et al. The Pediatric Hospital Medicine Core Competencies supplement: A framework for curriculum development by the Society of Hospital Medicine with acknowledgement to pediatric hospitalists from the American Academy of Pediatrics and the Academic Pediatric Association. J Hosp Med. 2010;5(Suppl 2):i-xv, 1-114. https://doi. org/10.1002/jhm.776

11. Maniscalco J, Gage S, Teferi S, Fisher ES. The Pediatric Hospital Medicine Core Competencies: 2020 revision; introduction and methodology. J Hosp Med. 2020;15(7):389-394. https://doi.org/10.12788/jhm.3391

12. Blum K. Raising the profile of hospital medicine. Hopkins Children's. 2018 Spring, p 32. Accessed January 16, 2020. https://www.hopkinsmedicine.org/ johns-hopkins-childrens-center/_documents/_publications/hopkins_childrens_magazine_spring2018.pdf
13. Roberts K, Stein R, Cheng T. The Academic Pediatric Association: The first fifty years. Acad Pediatr. 2011;11:173-180. https://doi.org/10.1016/j. acap.2011.02.001

14. Rauch DA, Lye PS, Carlson D, et al. Pediatric Hospital Medicine: A strategic planning roundtable to chart the future. J Hosp Med. 2012;7(4):329-334. https://doi.org/10.1002/jhm.950

15. Srivastava R, Landrigan CP. Development of the Pediatric Research in Inpatient Settings (PRIS) Network: Lessons learned. J Hosp Med. 2012;7(8)661664. https://doi.org/10.1002/jhm.1972

16. Freed GL, Uren RL. Hospitalists in children's hospitals: What we know now and what we need to know. J Pediatr. 2006;148(3):296-299. https://doi. org/10.1016/j.jpeds.2005.12.048

17. Maloney CG, Mendez SS, Quinonez RA, et al. The Strategic Planning Committee report: The first step in a journey to recognize pediatric hospital medicine as a distinct discipline. Hosp Pediatr. 2012;2(4):187-190. https://doi. org/10.1542/hpeds.2012-0048

18. Stevenson DK, McGuiness GA, Bancroft JD, et al. The Initiative on Subspecialty Clinical Training and Certification (SCTC): Background and recommendations. Pediatrics. 2014;133(Suppl 2):S53-S57. https://doi.org/10.1542/ peds.2013-3861C

19. Barrett DJ, McGuinness GA, Cunha CA, et al. Pediatric hospital medicine: A proposed new subspecialty. Pediatrics. 2017;139(3):e20161823. https://doi. org/10.1542/peds.2016-1823

20. Chang WW, Hopkins AM, Rehm KP, Gage SL, Shen M. Society of Hospital Medicine position on the American Board of Pediatrics response to the hospital medicine petition. J Hosp Med. 2019;14(10):589-590. https://doi. org/10.12788/jhm.3326

21. Nichols DG, Woods SK. The American Board of Pediatrics response to the pediatric hospital medicine petition. J Hosp Med. 2019:14:E1-E3. https://doi. org/10.12788/jhm.3322

22. American Academy of Pediatrics Section on Hospital Medicine. Guiding principles for pediatric hospitalist programs. Pediatrics. 2005;115:1101-1102.

23. American Academy of Pediatrics Section on Hospital Medicine. Guiding principles for pediatric hospitalist programs. Pediatrics. 2013;132(4):782-786. https://doi.org/10.1542/peds.2013-2269

24. Lye PS, American Academy of Pediatrics Committee on Hospital Care, Section on Hospital Medicine. Clinical report-physicians' roles in coordinating care of hospitalized children. Pediatrics. 2010;126(4):829-832.

25. Rauch DA, American Academy of Pediatrics Committee on Hospital Care, Section on Hospital Medicine. Physician's role in coordinating care of hospitalized children. Pediatrics. 2018;142(2):e20181503. https://doi.org/10.1542/ peds.2018-1503

26. Jerardi KE, Fisher ER, Rassbach $C$, et al; on behalf of the Council of Pediatric Hospital Medicine Fellowship Directors. Development of a curricular framework for pediatric hospital medicine fellowships. Pediatrics. 2019;140(1):e20170698. https://doi.org/10.1542/peds.2017-0698

27. American Board of Pediatrics. Pediatric hospital medicine entrustable professional activities. Accessed August 31, 2019. https://www.abp.org/subspecialty-epas\#Hospitalist\%20Medicine

28. Perkin RM, Swift JD, Newton DA (Eds). Pediatric Hospital Medicine: Textbook of Inpatient Management. Philadelphia, PA: Lippincott Williams \& Wilkins; 2003.

29. Frank F, Shah SS, Catallozzi M, Zaoutis L (Eds). The Philadelphia Guide: Inpatient Pediatrics. Philadelphia, PA: Lippincott Williams \& Wilkins; 2005

30. Zaoutis L, Chiang V (Eds). Comprehensive Pediatric Hospital Medicine. Philadelphia, PA: Mosby; 2007.

31. Rauch DA, Gershel J (Eds). Caring for the Hospitalized Child: A Handbook of Inpatient Pediatrics. Elk Grove Village, IL: American Academy of Pediatrics; 2013.

32. Rauch DA. Tribute to Jennifer Daru, MD. Hosp Pediatr. 2011;4(4):267-268. 